\title{
Calcification of Basal Ganglia in Chronic Hypoparathyroidism
}

\author{
Dr. Hamza Ali Khan*,Dr. Anurag Dhingra@ , Dr. Paul Peter\#, Dr. Giridhar Tarigopula\#, Dr Praveen Partha\# \\ *Specialist Registrar Department of Diabetes \& Endocrinology Darlington Memorial Hospital Darlington \\ @ST2 Department of Diabetes \& Endocrinology Darlingon Memorial Hospital \\ \#Consultant Department of Diabetes and Endocrinology Darlington Memorial Hospital Darlington
}

\section{Case Presentation}

-A 39 years old lady withType1Diabetes was repeatedly hospitalised with seizures thought to be related to hypoglycaemia though capillary

glucose was never documented in these episodes

-She also had primary hypoparathyroidism for the last ten years and was on calcium and vitamin D supplements

- She had cataract removal from right eye and also had early cataract in left eye

- Her family also confirmed her declining memory over past 2 years. She would take long pauses trying to recall things

- On examination she had slow speech, serpentine gaze and shuffling gait. Chvostek's sign and Trousseau's signs were negative.

Rest of the

systemic examination was normal

- Her calcium was reasonable with adjusted calcium of $2 .-2.5 \mathrm{mmol} / \mathrm{L}$ on treatment

\section{Progress and Management}

She was sent for neuropsychological assessment to ascertain the cognitive impairment and whether she would be capable of looking after her diabetes by herself. She was found to have marked cognitive impairment in everyday functioning, particularly planning \& organisation, abstract reasoning, attending to verbal information and processing new information, recalling and decision making. Thus had CT brain which showed wide spread calcification in the brain. She was seen by a neurologist and started on anticonvulsant treatment. Her seizures improved with no improvement in her cognition and gait abnormalities
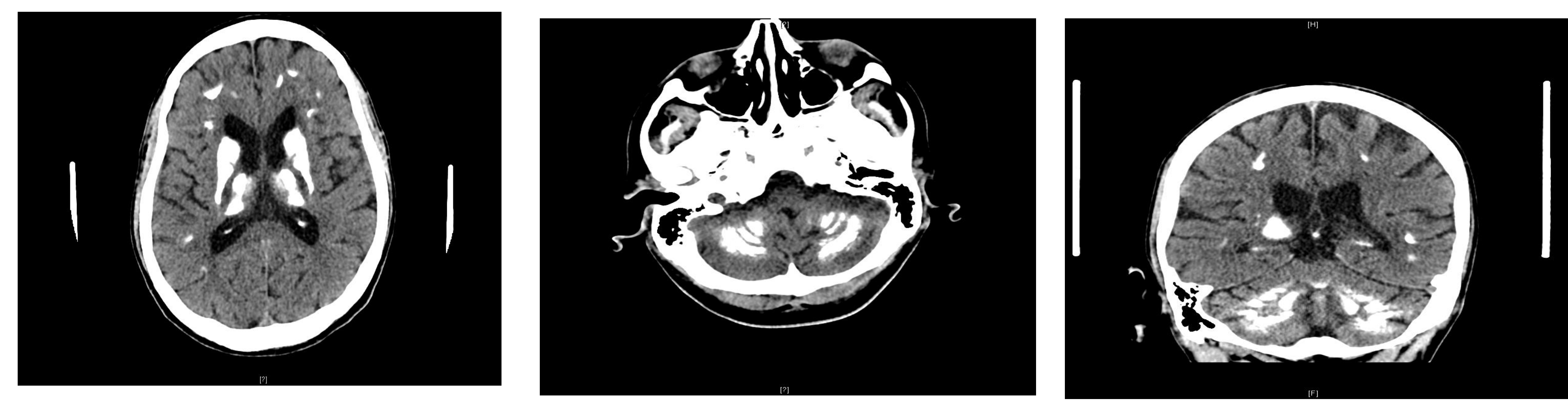

CT Brain-showing calcification in basal ganglia involving caudate nucleus,lentiform nucleus and thalamus, in the centrum seim ovale bilaterally \& also subcortical dense curvilinear calcification bilaterally

\section{Discussion}

-Hypoparathyroidism is the common cause of pathological calcification in the brain though $0.3-1.5 \%$ cases are physiological - Seizures occur in up to $70 \%$ of patients with symptomatic hypoparathyroidism ${ }^{1,2,3}$

-Parkinsonism, dystonia, hemiballismus, choreoathetosis, and oculogyric crises occur in $5-10 \%$ of patients with idiopathic hypoparathyroidism ${ }^{4}$ but are less common in patients with surgical hypoparathyroidism or other causes of hypocalcemia ${ }^{4}$ -Parkinsonism seems to be resistant to levodopa but in some cases improvement occur with calcium and vitamin D replacement $5,6,7$

-The mechanism of intracranial calcification is not completely understood 8 .It may be related to the duration of hypocalcaemia and hyperphosphataemia than parathyroid hormone itself

-The goal of therapy in hypoaparathyroidism is to control symptoms and minimise complications. Use of PTH is not recommended ${ }^{9}$ - In our case, initially hypoglycaemia was thought to be the cause of patient's seizures and neuropsychiatric symptoms as serum calcium was stable $(2.2-2.5 \mathrm{mmol} / \mathrm{L})$. However, her visit to the neurologist and subsequent $\mathrm{CT}$ brain findings and improvement in seizures (after anticonvulsant treatment) showed that her symptoms were due to hypothyroidism related brain calcification

\section{Conclusion}

This case emphasizes the importance of thinking about the whole spectrum of the disease even though the biochemical markers are stable on treatment.

\section{References}

1-Messing RO, Simon RP. Seizures as a manifestation of systemic disease. Neurol Clin 1986;4:563-584 2-Fonseca OA, Calverley JR. Neurological manifestations of hypoparathyroidism. Arch Intern Med 1967;120:202-206 3-Hossain M. Neurological and psychiatric manifestations in idiopathic hypoparathyroidism: response to treatment. J Neurol Neurosurg Psychiatry 1970;33:153-156

4-Rubenstein A, Brust JC. Parkinsonian syndrome as complication of post-thyroidectomy hypoparathyroidism. N Y State J Med 1974;74:2029-2030

5-Boy Frame, MD Parkinsonism in Postoperative Hypoparathyroidism archives of internal medicine sept.1965, vol 116. No3

6-Pearson DWM, Durward WF, Fogelman I, Boyle IT, Beastall G. Pseudohypoparathyroidism presenting as severe Parkinsonism. Postgrad Med J 198 1;57:445-7.

7-Soffer D, Licht A, Yaar I, Abramsky O. Paroxysmal choreoathetosis as a presenting symptom in idiopathic hypoparathyroidism. J Neurol Neurosurg Psychiatry 1977;40:692-694

9-Winer KK, Ko CW, Reynolds JC, et al. Long-term treatment of hypoparathyroidism: a randomized controlled study comparing parathyroid hormone (1-34) versus calcitriol and calcium. J Clin Endocrinol Metab 2003;88:4214-20 